\title{
Synthesis of 3Z-Nonenal and 3Z,6Z-Nonadienal
}

\author{
Tadahiko Kajiwara, Yoshinobu Odake and Akikazu Hatanaka \\ Department of Agricultural Chemistry, University of Yamaguchi, Yamaguchi
}

Received March 31, 1975

\begin{abstract}
$3 Z$-Nonenal and $3 Z, 6 Z$-nonadienal, potential biosynthetic precursors of $2 E$-nonenal and $2 E, 6 Z$-nonadienal, were for the first time synthesized stereoselectively.
\end{abstract}

In the previous paper, ${ }^{1)}$ the biosynthetic pathway of $2 E, 6 Z$-nonadienal (IV-a), $2 E$ nonenal (IV-b), and the corresponding alcohols was proposed as implicit in Scheme 1, on the basis of biochemical and chemical evidence; linolenic (I-a), linoleic acid (I-b), 3Z, 6Z-nonadienal (II-a) and 3Z-nonenal (II-b) were found in cucumbers, the latter aldehydes having been enzymatically derived from $\mathrm{I}-\mathrm{a}$ and $\mathrm{I}-\mathrm{b}$, respectively. These aldehydes were easily isomerized to the $2 E$-counterparts, IV-a and IV-b, respectively, which were further hydrogenated by alcohol dehydrogenase to the corresponding alcohols.

In the present paper, the first stereoselective synthesis of $3 Z, 6 Z$-nonadienal (II-a), $3 E$, 6Z-(XXIV), 2E,6Z-nonadienal (IV-a) and 3Znonenal (II-b) was described with special emphasis on the IR-, NMR- and MAS-spectral evidence for the structure and stereochemistry.

\section{[I] 3Z, 6Z-Nonadienal}

The stereoselective synthesis of $1 Z, 4 Z$ pentadienes of potential biological significance has not been established. Thus, $1 Z, 4 Z$-pentadienals have not been known so far. We succeeded for the first time in a highly stereoselective synthesis of $3 Z, 6 Z$-nonadienal (II-a) by means of stereoselective hydrogenation of diynol (XIV) followed by oxidation of $3 Z$, 6Z-nonadienol (III-a). This route of synthesis (Scheme 2) offers the advantage that sterically pure isomers can be obtained without contamination of other geometrical isomers by facile procedures.

The Grignard coupling of 3-butynyl- tetrahydropyranyl ether (VIII) ${ }^{2)}$ with bromopentyne (XI) gave nona-3, 6-diynyl-tetrahydro pyranyl ether (XIII) in good yield, which was contaminated by a small amount of isomeric impurities such as allens, and the product ether was used for further synthesis without purification. After removal of tetrahydropyranyl protective group, the resulting nonadiynol (XIV) was carefully rectified repeatedly on an effective column in vacuo.

Attempted stereoselective hydrogenation of nonadiynol (XIV) into 3Z,6Z-nonadienol (III-a) by the use of W-1 Raney nickel and the Lindlar catalyst in ethanol, methanol or ethyl acetate under various conditions was doomed to failure, since the resulted dienol (III-a) was contaminated with considerable amounts of geometrical isomers as indicated by VPC.

With P-2 nickel ${ }^{3)}$ prepared from nickel acetate and sodium borohydride, the diynol (XIV) was hydrogenated in ethanol containing a small amount of ethylenediamine, to afford the desired sterically pure $3 Z, 6 Z$-nonadienol (III-a) in nearly quantitative yield.

In the final stage, the unique oxidation of $3 Z, 6 Z$-nonadienol (III-a) with chromium trioxide-pyridine complex in methylene chloride and with DMSO-DCC- $\mathrm{P}_{2} \mathrm{O}_{5}$ afforded the corresponding aldehyde, $3 Z, 6 Z$-nonadienal (II-a) without shifting the double bonds into conjugation, and the yield was satisfactory. The products (II-a and III-a) thus obtained were practically free from any stereoisomers as evidenced by VPC, NMR and IR analyses. The structural confirmation was obtained 


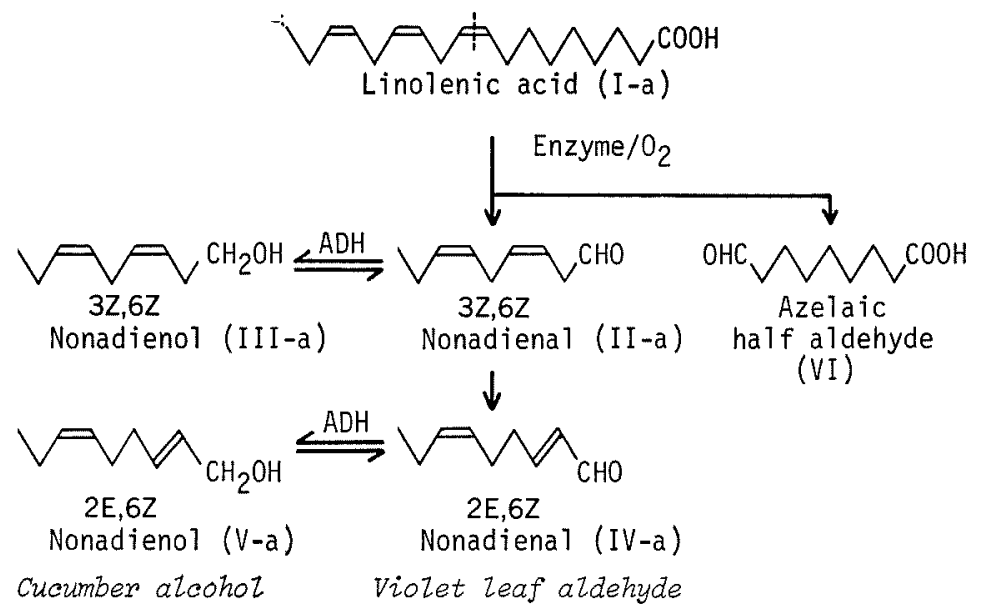

SCHEME 1. Biosynthetic Pathway of $3 Z, 6 Z$-Nonadienal.

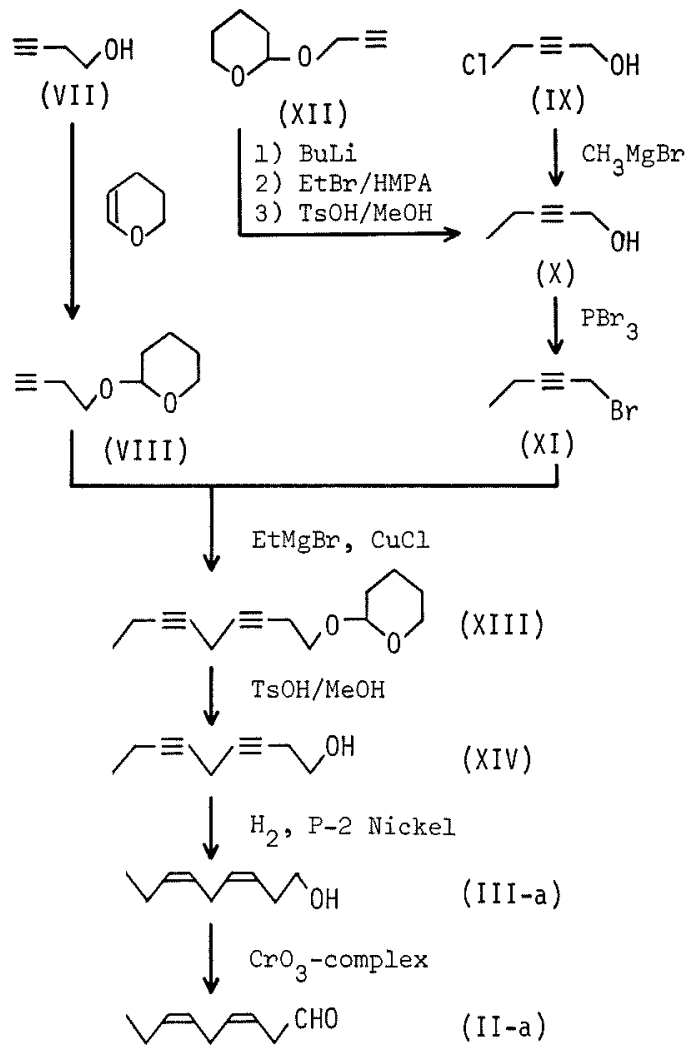

SCHEME 2. Synthesis of $3 Z, 6 Z$-Nonadienal.

by comparison with $3 E, 6 Z$ - (XXIV) and $2 E$, $6 Z$-nonadienal (IV-a) prepared by unequivocal routes as well as by comparison of NMR, IR and MAS spectra. The NMR-spectra of
$Z, Z$-isomer (II-a) and $E, Z$-counterpart (XXIV) were almost indistinguishable, only slight difference being observable in the olefinic region. The $Z, Z$-geometry was supported by the absence of a band at $973 \mathrm{~cm}^{-1}$ and by the presence of an absorption at $730 \mathrm{~cm}^{-1}$ The synthetic specimen was identified in every respect with the naturally derived $3 Z, 6 Z$-nonadienal from cucumbers.

\section{[II] 3Z-Nonenal}

3Z-Unsaturated aldehydes have not been prepared except 3Z-hexenal.4) The synthesis of 3Z-nonenal (II-b) was first achieved by the following Scheme 3 starting from 1,4-butenediol. The Grignard alkylation of 4-chloro-2Zbutenol (XV) gave $2 Z$-octenol (XVI) in quantitative yield, which on consecutive chlorination and cyanation with sodium cyanide in DMSO at room temperature, yielded $3 Z$-octenonitrile without rearrangement. Treatment of the nitrile with ethanolic hydrogen chloride gave 3Z-nonenoate (XVII) in good yield. 3ZNonenal (II-b) was obtained by lithium aluminium hydride reduction of the ester (XVII), followed by chromium trioxide oxidation of the resulting 3Z-nonenol (III-b) according to the procedure reported in the previous paper, ${ }^{4)}$ the yield being nearly quantitative. The structure was substantiated by NMR, IR and MAS spectroscopies and the identification was 


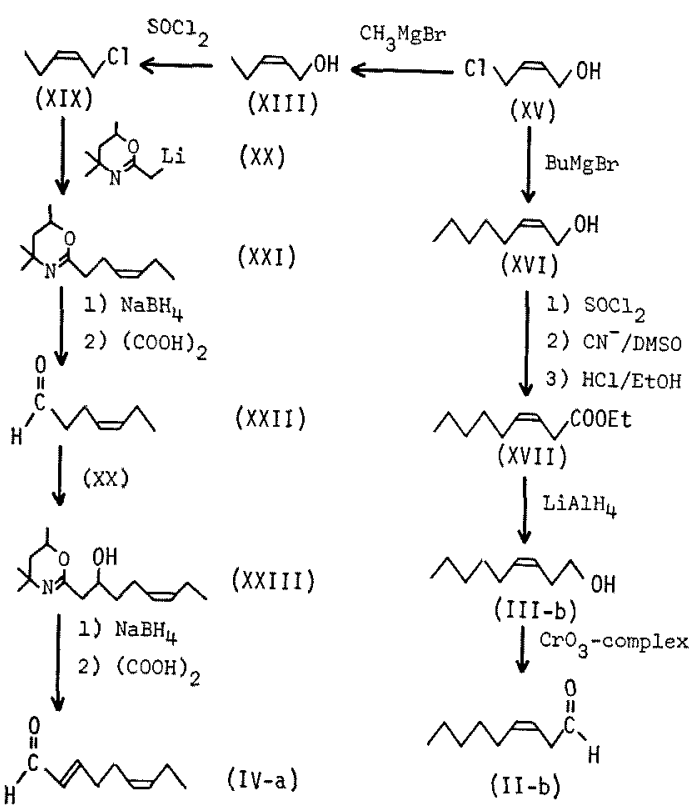

SCHEME 3. Synthesis of $3 Z$-Nonenal and $2 E, 6 Z$ Nonadienal.

also obtained with the naturally occurring aldehyde (II-b) from cucumbers.

\section{[III] $3 E, 6 Z$-, and 2E, 6Z-Nonadienal}

$2 E, 6 Z$-Nonadienal (IV-a) was obtained by successive dihydrooxazine homologations starting from 2Z-pentenyl chloride (XIX) according to Scheme 3.

The carbanion (XX) generated by the action of butyl lithium was alkylated with (XIX) to give the oxazine (XXI) without rearrangement, which was then subjected to borohydride reduction. Subsequent acid-hydrolysis of the dihydrooxazine gave 4Z-heptenal (XXII), which was free from contamination, in high yield. The aldehyde with the 2 carbonelongated chain was again condensed with oxazine lithiate $(\mathrm{XX})$ to give the corresponding hydroxyderivative (XXIII), which was not isolable by distillation. Fortunately, purification of the compound was not a necessary prerequisite to success of the overall sequence and this step was readily circumvented by the reduction of (XXIII) to the tetrahydro-1,3oxazine. In the final stage, the mild hydrolysis of the reduced oxazine with oxalic acid yielded violet leaf aldehyde, $2 E, 6 Z$-nonadienal (IV-a), which was then reduced with lithium aluminium hydride to cucumber alcohol (V-a). The process proceeded in a stereospecific manner and the yield was satisfactory. The structure was fully substantiated by NMR, IR and MAS spectral comparison, and the synthetic aldehyde was identified with the naturally occurring violet leaf aldehyde.

$3 E, 6 Z$-Nonadienal (XXIV) was prepared by the condensation of XXII with malonic acid in triethanolamine, followed by decarboxylation, lithium aluminium hydride reduction and chromium trioxide-pyridine complex oxidation in methylene chloride. The structure was confirmed by comparison with $3 Z, 6 Z$-nonadienal (II-a) obtained by unequivocal route (Scheme 2) as well as by NMR, IR and MAS spectral evidence. In accordance with expectation, the $E, Z$-geometry was supported by the absorption at 973 and $730 \mathrm{~cm}^{-1}$

\section{EXPERIMENTAL}

IR-spectra were recorded with a Hitachi EPI-G2. NMR-spectra were taken on a Varian Associates Model A-60 (60 MHz). MAS-spectra were on a Japan spectroscopic Model TAM-OISG spectrometer.

\section{[I] $3 Z, 6 Z$-Nonadienal (Il-a)}

2-(3'-Butynyloxy)-tetrahydropyrane (VIII). To a solution of 3-butynol (VII; $11.3 \mathrm{~g} ; 0.16$ mole) containing small amounts of $\mathrm{HCl}$ was dropwise added 2, 3-dihydropyrane $(16.0 \mathrm{~g} ; 0.19$ mole) with stirring. The reaction mixture was worked-up in an usual manner to give VIII $(24.0 \mathrm{~g} ; 97 \%)$, bp $90^{\circ} \mathrm{C}(14 \mathrm{mmHg}) . \operatorname{IR} \nu_{\max }^{\mathrm{film}} \mathrm{cm}^{-1}$ : $3250(\equiv \mathrm{CH}), 2100(-\mathrm{C} \equiv \mathrm{CH}), 1120(\mathrm{C}-\mathrm{O}-\mathrm{C})$.

2-Pentynol (X). a) 4-Chloro-2-butynol (IX; $77 \mathrm{~g} ; 0.74$ mole) obtained by mono-chlorination of butyne-1, 4-diol was added to Grignard reagent prepared from methyl bromide $(154 \mathrm{~g} ; 1.62$ mole) and magnesium $(39.4 \mathrm{~g} ; 1.62$ mole) in a mixed solvent of dry ether $(500 \mathrm{ml})$ and dry THF $(100 \mathrm{ml})$. After refluxing for $3 \mathrm{hr}$, the mixture was allowed to stand overnight. The reaction mixture was worked-up in an usual manner to afford $\mathrm{X}(50 \mathrm{~g} ; 78 \%)$, bp $65 \sim 75^{\circ} \mathrm{C}$ $(20 \mathrm{mmHg}) . \quad \mathrm{IR} \nu_{\max }^{\mathrm{fllm}} \mathrm{cm}^{-1}: 3300(-\mathrm{OH}), 2250,2200$ $(-\mathrm{C} \equiv \mathrm{C}-$ ).

b) To a stirred solution of pyranyl ether (XII; $28.0 \mathrm{~g} ; 0.2$ mole) in dry THF $(50 \mathrm{ml})$ and dry HMPA $(50 \mathrm{ml})$ was added $n$-butyllithium $(0.22$ mole $)$ in $n^{-}$ hexane keeping the temperature below $5^{\circ} \mathrm{C}$. After the 
mixture was stirred for $15 \mathrm{~min}$, ethyl bromide $(24.0 \mathrm{~g}$; 0.22 mole) in dry THF was added rapidly. After stirring for an additional $30 \mathrm{~min}$, the mixture was poured into a large volume of cold water and extracted with $n$-hexane. Pyranyl ether obtained thus was hydrolyzed with $\mathrm{TsOH}(1.0 \mathrm{~g})$ in methanol under refluxing for $2 \mathrm{hr}$. The mixture was poured into water and extracted with ether. After evaporation of ether, distillation of the residue gave $\mathrm{X}(5.2 \mathrm{~g} ; 31 \%), \mathrm{bp} 65 \sim$ $70^{\circ} \mathrm{C}(20 \mathrm{mmHg})$.

2-Pentynyl bromide $(X I)$. To a stirred solution of $\mathrm{X}(15.5 \mathrm{~g} ; 0.19$ mole $)$ and pyridine $(0.4 \mathrm{~g})$ in dry ether was added $\mathrm{PBr}_{3}(18.3 \mathrm{~g} ; 0.068$ mole). After refluxing for $2 \mathrm{hr}$, the mixture was cooled and upper layer was poured into ice. The reaction mixture was worked-up to give XI $(19.5 \mathrm{~g} ; 72 \%)$, bp $50^{\circ} \mathrm{C}(20 \mathrm{mmHg})$. $\mathrm{IR} \nu_{\mathrm{max}}^{\mathrm{f11m}} \mathrm{cm}^{-1}: 2200(-\mathrm{C} \equiv \mathrm{C}-), 610(\mathrm{C}-\mathrm{Br})$.

3,6-Nonadiynol $(X I V)$. A stirred solution of Grignard compound prepared from ethylmagnesium bromide ( $0.088 \mathrm{~mole})$ and VIII $(13.6 \mathrm{~g} ; 0.088 \mathrm{~mole})$ in dry THF was refluxed for $3 \mathrm{hr}$. The solution was cooled to $20^{\circ} \mathrm{C}$ and then cuprous chloride $(0.02 \mathrm{~g})$ was added with stirring. Bromide (XI; $11.8 \mathrm{~g} ; 0.08$ mole) in dry THF was added to the mixture, which was stirred for $3 \mathrm{hr}$ at $20^{\circ} \mathrm{C}$, then refluxed for an additional $16 \mathrm{hr}$. The reaction mixture was quenched and extracted with ether. Evaporation of solvent gave the crude compound (XIII), which was hydrolyzed with TsOH $(0.6 \mathrm{~g})$ in methanol under refluxing for $2.5 \mathrm{hr}$, to yield XIV $(6.8 \mathrm{~g} ; 62 \%)$, bp $115^{\circ} \mathrm{C}(15 \mathrm{mmHg}) . \quad I R \nu_{\max }^{f 11 m} \mathrm{~cm}^{-1}$ : $3350(-\mathrm{OH}), 2200(-\mathrm{C} \equiv \mathrm{C}-)$.

3Z, 6Z-Nonadienol (III-a). Diynol (XIV; $1.36 \mathrm{~g}$; 0.01 mole) was hydrogenated by flashing with hydrogen in the presence of $p-2$ nickel catalyst prepared from nickel acetate $(2.5 \mathrm{~g} ; 0.01 \mathrm{~mole})$ and the required quantity of $\mathrm{NaBH}_{4}$ in dry methanol containing ethylene diamine $(2.0 \mathrm{ml})$. The reaction mixture was workedup in an usual manner to give dienol (III-a; $0.76 \mathrm{~g}$; $54 \%$, bp $110^{\circ} \mathrm{C}(13 \mathrm{mmHg}) . \quad I R \Psi_{\max }^{\mathrm{fi} l \mathrm{~m}} \mathrm{~cm}^{-1}: 3300$ $(-\mathrm{OH}), 730(Z,-\mathrm{CH}=\mathrm{CH}-)$. NMR $\left(\mathrm{CDCl}_{3}\right): \delta 3.5$ $\left(2 \mathrm{H}, t, \mathrm{CH}-\mathrm{CH}_{2}-\mathrm{CH}\right), 5.3\left(4 \mathrm{H}, m,-\mathrm{CH}=\mathrm{CH}-\mathrm{CH}_{2}-\right.$ $\mathrm{CH}=\mathrm{CH}-$ ).

3Z, 6Z-Nonadienal (II-a). Chromium trioxide $(6.0 \mathrm{~g} ; 0.06 \mathrm{~mole})$ was added to a magnetically stirred solution of pyridine $(9.5 \mathrm{~g} ; 0.12$ mole) in methylene chloride $(150 \mathrm{ml})$. The solution was stirred for $15 \mathrm{~min}$ at room temperature, at the end of this period, a solution of dienol (III-a; $1.25 \mathrm{~g} ; 0.009$ mole) in a small volume of methylene chloride was added in one portion. After stirring for an additional $15 \mathrm{~min}$ at room temperature, the solution was decanted from the residue, which was washed with $200 \mathrm{ml}$ of ether. The combined organic solution was applied to a column of silica gel (Woelm) for dry-column chromatography and the eluate was washed with $1 \mathrm{~N} \mathrm{HCl}$ to remove a pyridine. The solvent was evaporated under nitrogen and the residue was distilled to give dienal (II-a; $1.2 \mathrm{~g} ; 98 \%$ ), bp $86 \sim 91^{\circ} \mathrm{C}(14 \mathrm{mmHg}) . \quad I R \nu_{\max }^{\mathrm{film}} \mathrm{cm}^{-1}: 1725(-\mathrm{CHO})$, $725(Z,-\mathrm{CH}=\mathrm{CH}-)$. MAS: $\mathrm{M}^{+} ; 138 \mathrm{~m} /$ e. 2, 4-DNPH*; $\operatorname{NMR}\left(\mathrm{CDCl}_{3}\right): \delta 0.95\left(3 \mathrm{H}, t, \mathrm{CH}_{3}-\mathrm{CH}_{2}-\right), 2.03(2 \mathrm{H}, p$, $\left.\mathrm{CH}_{3}-\mathrm{CH}_{2}-\mathrm{CH}=\right), 2.80\left(2 \mathrm{H}, t,=\mathrm{CH}-\mathrm{CH}_{2}-\mathrm{CH}=\right), 3.15$ $\left(2 \mathrm{H}, t,=\mathrm{CH}-\mathrm{CH}_{2}-\mathrm{CH}=\mathrm{N}-\right), 5.28,5.45(4 \mathrm{H}, m,-\mathrm{CH}=$ $\left.\mathrm{CH}-\mathrm{CH}_{2}-\mathrm{CH}=\overline{\mathrm{CH}}-\right), \quad 7.36 \quad\left(1 \mathrm{H}, \quad t,-\mathrm{CH}_{2}-\mathrm{CH}=\mathrm{N}-\right)$, $7 . \overline{75}(1 \mathrm{H}, d, \overline{\mathrm{H}} \mathrm{o}), \overline{8} .13\left(1 \mathrm{H}, d, d, \mathrm{Hm}^{\prime}\right), 8.95(1 \mathrm{H}, \bar{d}, \mathrm{Hm})$, $10.88(1 \mathrm{H}, s,=\mathrm{N}-\mathrm{NH}-)$.

\section{[II] 3Z-Nonenal $(I I-b)$}

2Z-Octenol $(X V I)$. The coupling of 4-chloro$2 Z$-butenol (XV; $26.6 \mathrm{~g} ; 0.25$ mole) with Grignard compound prepared from butyl bromide $(82.2 \mathrm{~g}$; 0.6 mole) and magnesium ( $14.4 \mathrm{~g} ; 0.6 \mathrm{~mole})$ afforded $2 Z$-octenol (XVI; $20.0 \mathrm{~g} ; 80 \%$ ), bp $105^{\circ} \mathrm{C}(20 \mathrm{mmHg})$. $\mathrm{IR} \nu_{\max }^{\mathrm{fi} \lim } \mathrm{cm}^{-1}: 3300(-\mathrm{OH}), 730(Z,-\mathrm{CH}=\mathrm{CH}-)$.

Ethyl-3Z-nonenoate $(X V I I) . \quad 2 Z$-Octenyl chloride $(6.3 \mathrm{~g} ; 0.05$ mole) prepared by chlorination of XVI was added to a solution of DMSO $(50 \mathrm{ml})$ containing sodium cyanide $(5.0 \mathrm{~g} ; 0.10 \mathrm{~mole})$. The reaction mixture was worked-up in an usual manner to give $3 Z$ octenonitrile $(3.5 \mathrm{~g} ; 60 \%)$, which was dissolved in ethanol and hydrogen chloride was slowly passed through the solution for $1 \mathrm{hr}$. The mixture was brought to gentle reflux for an additional $12 \mathrm{hr}$. The reaction mixture was filtered and diluted with water, and then neutrized with $5 \% \mathrm{Na}_{2} \mathrm{CO}_{3}$, extracted with ether. Drying and concentration left a crude oil, which was distilled to give XVII $(2.7 \mathrm{~g} ; 78 \%)$, bp $102^{\circ} \mathrm{C}$ $(20 \mathrm{mmHg}) . \quad \mathrm{IR} \nu_{\max }^{\mathrm{film}} \mathrm{cm}^{-1}: 1725$ (-COOEt), $720(Z$, $-\mathrm{CH}=\mathrm{CH}-$ ).

3Z-Nonenol $(I I I-b)$. Reduction of XVII with $\mathrm{LiAlH}_{4}(2.7 \mathrm{~g} ; 0.04$ mole $)$ in an usual manner gave the corresponding alcohol (III-b; $1.5 \mathrm{~g} ; 57 \%$ ), bp $97^{\circ} \mathrm{C}$ $(17 \mathrm{mmHg}) . \quad \mathrm{IR} \nu_{\max }^{\mathrm{film}} \mathrm{cm}^{-1}: 3300(-\mathrm{OH}), 725(Z$, $-\mathrm{CH}=\mathrm{CH}-$ ).

3Z-Nonenal $(I I-b)$. According to the same manner mentioned above, III- $\mathrm{b}(1.0 \mathrm{~g} ; 0.007$ mole) was oxidized with chromium trioxide-pyridine complex in methylene chloride to the corresponding aldehyde (II-b; $0.95 \mathrm{~g}$; $97 \%)$, bp $91^{\circ} \mathrm{C}(20 \mathrm{mmHg}), \quad$ IR $\nu_{\max }^{\text {film }} \mathrm{cm}^{-1}: 1725$ $(-\mathrm{CHO}), 720(\mathrm{Z},-\mathrm{CH}=\mathrm{CH}-)$.

[III] 2E, 6Z- $(I V-a)$ and 3E, 6Z-Nonadienal (XXIV) $2 Z$-Pentenyl chloride $(X I X)$. According to the procedure previously reported, ${ }^{4)} 2 Z$-pentenyl chloride (XIX) was prepared by methylation of 4-chloro-2Zbutenol (XV) via Grignard compound followed by

* DNPH: Dinitrophenyl hydrazone. 2, 4-DNPH of II-a was prepared according to the procedure previously reported. ${ }^{4}$ 
chlorination of $2 Z$-pentenol (XIII), bp $55^{\circ} \mathrm{C}(60 \mathrm{mmHg})$.

4Z-Heptenal $(X X I I)$. To a stirred solution of 2,4 , 4, 6-tetramethyl-5, 6-dihydro-1, 3-oxazine (14.1 g; 0.10 mole) in dry THF was added dropwise $n$-butyllithium $\left(0.11\right.$ mole) in $n$-hexane at $-78^{\circ} \mathrm{C}$. After stirring for $1 \mathrm{hr}$, the mixture was formed yellow precipitate, which was indicative of lithio anion (XX) formation. 2Z-Pentenyl chloride (XIX; $11.3 \mathrm{~g} ; 0.11$ mole) in dry THF was added to the mixture. The reaction mixture was allowed to slowly warm to room temperature. After standing for $1 \mathrm{hr}$, the mixture was poured into ice-water and was acidified $(\mathrm{pH} \mathrm{2})$ with $6 \mathrm{~N} \mathrm{HCl}$. The acidic solution was extracted with $n$-hexane (discarded) and made basic by the careful addition of $40 \%$ $\mathrm{NaOH}$ solution. The resulting oil was extracted with ether and the extract was dried over anhydrous $\mathrm{K}_{2} \mathrm{CO}_{3}$. Evaporation of ether gave crude XXI, which was dissolved in ethanol $(100 \mathrm{ml})$ and THF $(100 \mathrm{ml})$ without further purification. The solution was cooled to $-40^{\circ} \mathrm{C}$ and then $\mathrm{NaBH}_{4}(4.15 \mathrm{~g} ; 0.11$ mole) solution and $6 \mathrm{~N}$ $\mathrm{HCl}$ solution were introduced to the stirred solution alternately so that $\mathrm{pH} 6 \sim 8$ was maintained. After stirring for an additional $1 \mathrm{hr}$ at $-40^{\circ} \mathrm{C}$, the contents were poured into water and made basic by the addition of $25 \% \mathrm{NaOH}$ solution. The mixture was extracted with ether and the extracts were washed with sat. $\mathrm{NaCl}$, and dried over anhydrous $\mathrm{K}_{2} \mathrm{CO}_{3}$. After removal of solvent, a mixture of the residue and hydrated oxalic acid $(12.5 \mathrm{~g})$ dissolved in water was steam-distilled until the distillate was free from organic materials. The distillate was saturated with $\mathrm{NaCl}$ and extracted with ether. The extracts were dried over anhydrous $\mathrm{Na}_{2} \mathrm{SO}_{4}$ and distillation gave XXII $(2.5 \mathrm{~g} ; 22.3 \%)$, bp $54 \sim 58^{\circ} \mathrm{C}$ $(21 \mathrm{mmHg}) . \operatorname{IR} v_{\max }^{\text {film }} \mathrm{cm}^{-1}: 1725$ (-CHO), $730(Z$, $-\mathrm{CH}=\mathrm{CH}-$ ).

$2 E, 6 Z$-Nonadienal $(I V-a)$. Oxazine derivative (XXIII) was prepared by condensation of aldehyde (XXII; $2.5 \mathrm{~g} ; 0.022$ mole) and lithio anion (XX; 0.02 mole) according to the procedure mentioned above. Hydroxyloxazine (XXIII) was reduced with $\mathrm{NaBH}_{4}$ and hydrolysis of the reduced oxazine with oxalic acid gave $2 E, 6 Z$-nonadienal (IV-a; $0.83 \mathrm{~g} ; 30 \%$ ), bp $94 \sim$ $98^{\circ} \mathrm{C}(11 \mathrm{mmHg}) . \quad$ IR $\nu_{\max }^{\mathrm{fim}} \mathrm{cm}^{-1}: 1725(-\mathrm{CHO}), 990$ $(E,-\mathrm{CH}=\mathrm{CH}-), 730(Z,-\mathrm{CH}=\mathrm{CH}-)$.

$2 E, 6 Z$-Nonadienal (IV-a) was reduced to cucumber alcohol, 2E, 6Z-nonadienol (V-a), with $\mathrm{LiAlH}_{4}$ in an usual manner.

3E, 6Z-Nonadienal (XXIV). According to the procedure of Jutz, $\left.{ }^{6}\right) 3 E, 6 Z$-nonadienoic acid $(4.2 \mathrm{~g} ; 88 \%)$ was prepared by condensation of $4 Z$-heptenal (XXII; $3.5 \mathrm{~g} ; 0.031$ mole) with malonic acid ( $3.2 \mathrm{~g} ; 0.031$ mole) in triethanolamine $(4.17 \mathrm{~g} ; 0.028$ mole $)$ followed by decarboxylation. $3 E, 6 Z$-Nonadienol $(2.9 \mathrm{~g} ; 76.7 \%)$ was obtained by esterification of $3 E, 6 Z$-nonadienoic acid ( $4.2 \mathrm{~g} ; 0.027$ mole) with $\mathrm{CH}_{2} \mathrm{~N}_{2}$ followed by reduction with $\mathrm{LiAlH}_{4}$. The alcohol $(1.4 \mathrm{~g} ; 0.01$ mole) was oxidized by chromium trioxide-pyridine complex in methylene chloride to the corresponding aldehyde (XXIV; $0.8 \mathrm{~g} ; \quad 60 \%$ ). bp $94 \sim 95^{\circ} \mathrm{C} \quad(22 \mathrm{mmHg}$ ). $\mathrm{IR}: \mathrm{max}_{\max }^{\mathrm{fllm}} \mathrm{cm}^{-1}: 1725(-\mathrm{CHO}), 973(E,-\mathrm{CH}=\mathrm{CH}-), 730$ $(Z,-\mathrm{CH}=\mathrm{CH}-)$.

Acknowledgement. The authors wish to express their thanks to Prof. Y. Inouye, Institute for Chemical Research Kyoto University for NMR and MAS spectra throughout this work.

\section{REFERENCES}

1) A. Hatanaka, T. Kajiwara and T. Harada, Phytochem., 14, (1975), in press.

2) M. Schwartz and R. M. Waters, Synthesis, 1972, 567.

3) C. A. Brown and V. K. Ahuja, J. C. S. Chem. Comm., 1973, 533.

4) T. Kajiwara, T. Harada and A. Hatanaka, Agr. Biol. Chem., 39, 243 (1975).

5) A. I. Meyers, A. Nabeya, H. W. Adickes, I. R. Politzer, G. R. Malone, A. C. Kovelesky, R. L. Nolen and R. C. Portnoy, J. Org. Chem., 38, 36 (1973).

6) C. Jutz, Chem. Ber., 92, 1983 (1959). 